\title{
Diet selection - an ecological perspective
}

\author{
B Y R. MOSS \\ Institute of Terrestrial Ecology, Banchory, Grampian AB31 $4 B Y$
}

The traditional role of agricultural research has been to maximize the efficiency of food production. Agriculture has advanced by progressively removing nutritional, environmental and genetic constraints on production from organisms whose properties lend themselves to this endeavour.

Shelter is provided for our domestic animals. Contact with natural enemies such as predators, parasites and disease organisms is minimized, as is competition for resources with other species. Seasonal shortages of food are avoided and foraging is greatly simplified. The need to seek out a mate is largely eliminated; indeed, large modern breeds of turkeys can no longer mate naturally.

Competition with conspecifics for resources such as food, shelter and mates has largely disappeared. Weapons and rituals that once played essential roles in the search for social status, and the access to resources which status ensures, are now functionless relics of a more natural past. Natural selection for fit, competitive and resourceful animals has been replaced by selective breeding. One result of this is that domestic animals have smaller brains than their wild counterparts and the more recently evolved ('higher') parts of their brains have degenerated most (Herre \& Röhrs, 1973).

The properties of wild plants can be seen largely as consequences of two broad evolutionary pressures: their physical environment and interactions with other organisms. An important set of interactions is with animals which eat plants. Being eaten in part can be useful to plants in dispersing propagules. It can also, however, be disadvantageous and plants have evolved many defences against herbivores, defences such as spikes, toxins and digestion inhibitors. In turn, herbivores have evolved means for overcoming these defences. Such interactions have been regarded as a sort of evolutionary arms race.

Each plant has limited resources. Resources allocated to the synthesis of defences or competing with other plants may not be available for growth and reproduction. A plant can defend itself and compete effectively with others in only a limited set of circumstances, in its own ecological niche. The characteristics of a species are in general adapted to efficient exploitation of the ecological niche which it inhabits. 'Efficiency' in the ecological context is not, of course, the same as agricultural or productive efficiency: ecological efficiency is more closely allied to the concept of evolutionary fitness.

The breeding of domestic plants for agriculture has, in part, been concerned with eliminating structures which were once ecologically useful but which do not now contribute to agricultural production. The metabolic resources which were once used to synthesize tall stems or toxic molecules have been channelled into more useful forms of protoplasm. Of course, many biologically active molecules with antibacterial, insecticidal or other useful properties form remedies, drugs and spices and so the evolutionary arms race has provided some weapons which we have captured and use to our own advantage.

Most parts of most plants are inedible to most wild herbivores. Diet selection enables a wild animal to utilize the limited range of plant parts to which it is adapted. Domestic 
animals do not have the same choices as wild ones, but they do show certain residual preferences. To understand the evolution of these residua, we must look to the natural world.

\section{DIET SELECTION BY WILD HERBIVORES}

Diet selection and competition. Species which exist today survived and reproduced effectively in the past. To do this, individuals had to meet competition from other species and from individuals of the same species. This may help to explain why wild animals often eat certain foods whilst ignoring others which seem to be nutritionally adequate and which are eaten by closely related species, or even by different populations of the same species. An individual presumably shows preferences based on archetypes which ensured the genetic survival of its progenitors. This thought may be put teleologically by saying that an animal chooses foods which maximize its genetic fitness.

A species may survive competition from other species by specializing, by becoming more proficient at foraging for a restricted range of foods and more efficient at digesting them than if it attempted to take a more catholic diet. Thus, in interior Alaska the closely-related willow ptarmigan (Lagopus lagopus) and rock ptarmigan (Lagopus mutus) co-exist on the same wintering grounds. The winter diet of the willow ptarmigan here is over $90 \%$ willow (Salix spp.), that of the rock ptarmigan over $90 \%$ birch (Betula spp.). This occurs irrespective of whether both species are feeding close together or whether only one species is present and has the choice of willow or birch (Moss, 1974). Nonetheless, willow ptarmigan are quite capable of subsisting on birch and do so in parts of their range where little willow is available (Pulliainen \& Iivanainen, 1981). Similarly, rock ptarmigan can subsist on willow; indeed, they prefer it to birch in Iceland, where there are no willow ptarmigan with which to compete (Gardarsson \& Moss, 1970). In Alaska, then, it appears that interspecific competition has caused the observed differences in diet selection and that the socially dominant willow ptarmigan (Moss, 1973) has gained access to the intrinsically more nutritious (Moss, 1983) willow. However, in Alaska each species has become adapted to its own particular diet, as shown by interspecific differences in bill sizes (Weeden, 1969), gut lengths and gizzard weights (Moss, 1974). It seems reasonable to suggest that birch-adapted birds eating birch are likely to perform less well than willow-adapted birds eating willow, but better than birch-adapted birds eating willow.

Individuals of the same species also compete with each other. One sex or age-class may dominate another and so gain access to better food. Thus, old male black grouse (Tetrao tetrix) dominate females and young males at feeding sites (Marjakangas. 1989) and have relatively short guts, an indication that they eat a more digestible diet (Moss, 1983). Within a sex or age-class, dominant individuals are likely to have the best diet. At the same time, a good-quality diet may contribute to an individual's competitive abilities. Socially subordinate animals may die either because they starve due to a shortage of food (Murton et al. 1966) or because they cannot utilize available food due to the workings of a social system (Moss \& Watson, 1985).

The idea that selection for the best food contributes to an animal's competitive ability, social status and genetic fitness can explain the observation that entire populations of a species may ignore an abundant potential food which is much used by other populations of the same species. Thus, capercaillie (Tetrao urogallus) prefer needles of Scots pine 
(Pinus sylvestris) as a winter food and will select it in preference to Norway spruce (Picea abies), even when the latter is far more abundant. However, populations can overwinter on Norway spruce needles in the absence of pine (Dement'ev \& Gladkov, 1952). It is reasonable to suggest that, although Norway spruce is an adequate food, eating pine may provide birds with a competitive advantage over Norway spruce-eaters. From an agricultural perspective, this might seem an inefficient use of resources. From an ecological viewpoint, agricultural efficiency is irrelevant to the process of natural selection.

Diet selection and plant defences. There is much literature on the defences of plants against herbivores (Rosenthal \& Janzen, 1979; Crawley, 1983). Plants may make themselves unattractive by structural defences, or by infusing their substance with toxins or digestion-inhibitors. It has been argued (Swain, 1979) that polyphenols, tannins and lignins, 'are the most important components of plants - not only because of their widespread, almost universal distribution, but also because their evolutionary history is longer than that of any other class of secondary plant constituents'. Two primary functions of polyphenols are to impart structure to woody plants and to defend tissues against attack by fungi and bacteria. In addition, the dilution of protein by lignocellulose and the inhibition of protein digestion by tannins deter consumption by herbivores. Much agricultural research has been aimed at subverting these two defences by adding proteins to compounded diets and by increasing the digestibility of dietary fibre.

In general, plants constitute a potential source of nutrients and energy for domestic herbivores. Many of the properties of plants have evolved as defences against herbivory. Agricultural research aims to overcome these defences.

\section{THREE ECOLOGICAL CONCEPTS}

Specialists and generalists. The main advantage of a specialized diet is that specialists can develop morphological and metabolic means of exploiting defended resources not available to generalists. Some invertebrate herbivores eat only one food-plant species but such monophagy does not occur in vertebrates. Vertebrate specialists such as the koala bear (Phascolarctos cinereus) and giant panda (Ailuropoda melanoleuca) eat several species of Eucalyptus and bamboo respectively, as well as other plants, and, in the case of the giant panda, some small animals too. Nonetheless the koala, for example, does show very specialized detoxification mechanisms (Degabriele, 1980).

A generalist herbivore can exploit a range of food plants, some of which may be only temporarily abundant. A mixed diet may also be a balanced diet, one plant providing nutrients which are lacking in another. Indeed, a mixed diet may be obligatory for the generalist eating defended plants since the animal's detoxification mechanisms may not be able to cope with a large dose of one toxin.

Heritability of plant defences. It was once thought that traits important to genetic fitness would show little genetic variance. The argument was that natural selection should have fixed such traits at their optimum. Genes which caused deviation from this optimum would have been selected against. Implicit in this argument were the assumptions that selective pressure remained constant, in a constant environment. We now understand that neither of these assumptions is true and that components of genetic fitness can be highly heritable.

In particular, toxic factors affecting food selection can show much genetic variance. 
Snowshoe hares (Lepus americanus) prefer strains of Douglas fir (Pseudotsuga menziesii) with relatively low levels of resins, oxygenated monoterpenes and phenolic compounds, and the relative palatability of different strains of fir is highly heritable (Crawley, 1983).

If all plants of one species had exactly the same defences, these would be highly predictable and a herbivore could develop precisely and efficiently adapted detoxification mechanisms. Genetic variability, however, ensures that some individual plants are less palatable than others and so less likely to be eaten. Hence genetic variability can be adaptive. It has also enabled plant breeders to select for strains of plants with low toxicity.

Optimal foraging. In an attempt to understand foraging behaviour ecologists have developed the idea of optimal foraging. The fundamental idea is that evolution is an optimizing process. The method is to describe the constraints and opportunities offered to an animal to achieve a certain goal; for example, maximization of the net rate of energy intake. The ecologist then constructs a model which achieves this goal and observes wild animals to see if their behaviour fits the model. If it does, he assumes that he has uncovered the evolutionary pressures which determined the animal's behaviour.

This approach seems to imply that evolution acts as if by design. It borders on the teleological and is reminiscent of Pangloss's dictum: 'All is for the best in the best of all possible worlds'. Alternatively, mechanistic models often give equally good, or better, fits to the data. Nonetheless, the idea that all traits have, or have had, a useful function has proved invaluable in developing our understanding of evolution.

\section{IMPACTS OF MAN}

In principle, it can be argued that there is nothing new in man's impact on the biosphere, that it is simply part of a natural evolutionary progression. Certainly our impact does not yet compare with that which the oxygen produced by the first green plants must have had on the aboriginal anaerobes.

Nonetheless, there is a good case that 'objective knowledge' (Popper, 1979), the development and storage of abstract concepts and models, is a new development. In particular, man can set himself abstract objectives and pursue them in a co-operative spirit mediated through shared ideals. For example, the main goal of the agricuitural research community seems to have been to maximize production, irrespective of the other effects we may have on the organisms we utilize.

Many of the behaviour patterns which remain in our domestic animals are mere fragments of once-integrated displays or once-coordinated sequences of activity. In an ecological context, we can usually understand diet selection in terms of its function in contributing to an animal's fitness. In an agricultural context, aspects of diet selection may no longer have their original function and will, therefore, be difficult to understand.

\section{REFERENCES}

Crawley, M. J. (1983). Herbivory: The Dynamics of Animal-Plant Interactions. Oxford: Blackwell Sicientific Publications.

Degabriele. R. (1980). The physiology of the koala. Scientific American 243, 94-99.

Dement'ev. G. P. \& Gladkov, N. A. (editors) (1952). In Birds of the Soviet Union, vol. 4. Moscow: Nauka. Translation (1967) from Russian by Israel Program for Scientific Translations.

Gardarsson, A. \& Moss, R. (1970). Selection of food by Icelandic ptarmigan in relation to its availability and nutritive value. Symposia of the British Ecological Sociery 10, 47-71. 
Herre, W. \& Röhrs, M. (1973). Haustiere-zoologisch Gesehen. Stuttgart: Gustav Fischer Verlag.

Marjakangas, A. (1989). Social organization in flocks of the black grouse (Tetrao tetrix) in winter. Abstracts of the Nordic Congress on Game Research 11, 44.

Moss, R. (1973). The digestion and intake of winter foods by wild ptarmigan in Alaska. Condor 75, $293-300$.

Moss. R. (1974). Winter diets, gut lengths, and interspecific competition in Alaskan ptarmigan. Auk 91, 737-746.

Moss, R. (1983). Gut size, body weight, and digestion of winter foods by grouse and ptarmigan. Condor 85 , 185-193.

Moss, R. \& Watson, A. (1985). Adaptive value of spacing behaviour in population cycles of red grouse and other animals. Symposia of the British Ecological Society 25, 275-294.

Murton, R. K., Isaacson, A. J. \& Westwood, N. J. (1966). The relationships between wood-pigeons and their clover food supply and the mechanisms of population control. Journal of Applied Ecology 3, 55-96.

Popper, K. R. (1979). Objective Knowledge. Oxford: Clarendon Press.

Pulliainen, E. \& Iivanainen, J. (1981). Winter nutrition of the willow grouse (Lagopus lagopus L.) in the extreme north of Finland. Annales Zoologici Fennici 18, 263-269.

Rosenthal, G. A. \& Janzen, D. H. (editors) (1979). Herbivores: Their Interaction with Secondary Plant Metabolites. New York: Academic Press.

Swain, T. (1979). Tannins and lignins. In Herbivores: Their Interaction with Secondary Plant Metabolites, pp. 657-682. New York: Academic Press.

Weeden, R. (1969). Foods of Rock and Willow Ptarmigan in central Alaska with comments on interspecific competition. Auk 86, 271-281. 